\title{
Postsynaptic Targets of Type II Auditory Nerve Fibers in the Cochlear Nucleus
}

\author{
Thane E. Benson ${ }^{2}$ and M. Christian Brown ${ }^{1,2}$ \\ ${ }^{1}$ Department of Otology and Laryngology, Harvard Medical School, Boston, MA 02115, USA \\ ${ }^{2}$ Eaton-Peabody Laboratory, Massachusetts Eye and Ear Infirmary, Boston, MA 02114, USA
}

Received: 25 July 2003; Accepted: 28 October 2003; Online publication: 4 May 2004

\section{ABSTRACT}

Type II auditory nerve fibers, which provide the primary afferent innervation of outer hair cells of the cochlea, project thin fibers centrally and form synapses in the cochlear nucleus. We investigated the postsynaptic targets of these synapses, which are unknown. Using serial-section electron microscopy of fibers labeled with horseradish peroxidase, we examined the border of the granule-cell lamina in mice, an area of type II termination that receives branches having swellings with complex shapes. About $70 \%$ of the swellings examined with the electron microscope formed morphological synapses, which is a much higher value than found in previous studies of type II swellings in other parts of the cochlear nucleus. The high percentage of synapses enabled a number of postsynaptic targets to be identified. Most of the targets were small dendrites. Two of these dendrites were traced to their somata of origin, which were cochlear-nucleus "small cells" situated at the border of the granule-cell lamina. These cells did not appear to receive any terminals containing synaptic vesicles that were large and round, indicating a lack of input from type I auditory nerve fibers. Nor did type II swellings or targets participate in the synaptic glomeruli formed by mossy terminals and the dendrites of granule cells. Other type II synapses were axosomatic and their targets were large cells, which were presumed multipolar cells and one cell with characteristics of a globular bushy cell. These large cells almost certainly receive additional input from

Correspondence to: M. Christian Brown • Eaton-Peabody Laboratory • Massachusetts Eye and Ear Infirmary $\cdot 243$ Charles Street • Boston, MA 02114 - Telephone: (617) 573-3875; Fax: (617) 720-4408; email: mcb@ep1.meei.harvard.edu type I auditory nerve fibers, which provide the afferent innervation of the cochlear inner hair cells. A few type II postsynaptic targets-the two small cells as well as a large dendrite-received synapses that had accompanying postsynaptic bodies, a likely marker for synapses of medial olivocochlear branches. These targets thus probably receive convergent input from type II fibers and medial olivocochlear branches. The diverse nature of the type II targets and the examples of segregated convergence of other inputs illustrates the synaptic complexity of type II input to the cochlear nucleus.

Keywords: outer hair cell, olivocochlear, small cell, multipolar cell, granule cell

\section{INTRODUCTION}

Auditory nerve fibers encode information about sound stimuli that is sent from the cochlea to the cochlear nucleus of the brainstem. The neurons that give rise to these fibers have been subdivided into two types depending on which receptor cell population is contacted in the cochlea. Type I neurons provide the afferent innervation of inner hair cells, whereas type II neurons provide the afferent innervation of outer hair cells (Spoendlin 1971; Kiang et al. 1982). It is clear that type I neurons, which comprise more than $90 \%$ of all primary auditory neurons, provide the main pathway for auditory input to the brain. These neurons respond to sound and transmit this information to the cochlear nucleus via their fast-conducting fibers (reviewed by Ruggero 1992). The type II neurons make up the remaining small percentage of primary auditory neurons (Spoendlin 1969; 
Morrison et al. 1975; Kiang et al. 1984; Brown 1987; Romand and Romand 1987), and their thin fibers provide a presumably slow-conducting pathway into the brain. The function of these neurons is unknown because physiological studies suggest that they do not respond to sounds typically used as search stimuli (Robertson 1984; Brown 1994; Robertson et al. 1999). Difficulties in recording from their thin fibers and their infrequent number have hindered progress in this area. Anatomical study of type II neurons is a parallel approach that may yield clues to their functional roles.

Both type I and type II neurons project fibers centrally from the cochlea into the auditory nerve (Fig. 1) and terminate in the cochlear nucleus (Lorente de No 1933; Fekete et al. 1984; Brown et al. 1988a). Type I fibers have an excitatory influence on their postsynaptic targets, leading to discharge of cochlear-nucleus neurons (Pfeiffer 1966; Golding et al. 1995; Kopp-Scheinpflug et al. 2002). Type I targets in the cochlear nucleus are a variety of types of neurons (Brawer and Morest 1975; Rouiller et al. 1986), which have been classified by their morphology using different stains (Osen 1969; Brawer et al. 1974). The postsynaptic targets of type II fibers in the cochlear nucleus are almost entirely unknown. Research has progressed slowly because type II fibers are scarce and because many of their swellings do not form synapses (Ryugo et al. 1991; Berglund et al. 1996). Those few synapses that have been found were on dendrites that could not usually be traced to their cell bodies of origin. The above studies examined type II fibers mainly in the magnocellular core of the cochlear nucleus, which is the main part of the nucleus containing the large neurons that project in turn to higher centers of the auditory brainstem.

We now take an approach that aims to identify targets of type II fibers in a noncore region of the cochlear nucleus, the granule-cell lamina. The lamina is a region of granule cells that separates the ventral from the dorsal subdivision of the cochlear nucleus (Mugnaini et al. 1980a). Type II fibers project in and along the border of the lamina, forming en passant swellings with shapes that often have angular edges and complex shapes (Brown and Ledwith 1990). One idea is that these swellings are more likely to form synapses than the smoother, ellipsoidal swellings that occur on type II fibers in the core of the cochlear nucleus (Brown and Ledwith 1990). This idea arises from the observation that ellipsoidal swellings can even be found in nonsynaptic areas such as the auditory nerve (Brown 1987; Brown and Ledwith 1990). Ellipsoidal swellings may thus arise merely as a consequence of the few organelles they contain. In the lamina, type II fibers are relatively isolated from the more numerous terminations of type I fibers that are restricted to the core (Brown et al. 1988a; Brown and Ledwith 1990; Berglund and Brown 1994). Perhaps this segregation results from type II fibers projecting to unique targets in the lamina; whatever the reason, the offset allows study of labeled type II fibers in relative isolation. The lamina receives input from type II fibers from all regions of the cochlea (Berglund and Brown 1994). Thus, for several reasons, the granule-cell lamina offers a promising site to examine type II swellings for their synapses and their postsynaptic targets. In addition to type II inputs, the lamina also receives a wide variety of auditory descending inputs from sources such as the superior olivary complex (Rasmussen 1960; Martin 1981; Osen et al. 1984; Ryan et al. 1987; Brown et al. 1988b), inferior colliculus (Caicedo and Herbert 1993; Saldana 1993), and auditory cortex (Weedman and Ryugo 1996). Additional inputs arise from nonauditory sources (Itoh et al. 1987; Weinberg and Rustioni 1987; Burian and Gstoettner 1988; Kevetter and Perachio 1989). The granule-cell lamina thus offers the opportunity to study convergence of other inputs onto the targets of type II fibers. The present work demonstrates that in the lamina, a high percentage of type II swellings do form synapses. Perhaps as a consequence of the relatively large number of synaptic swellings that were found, a number of neurons that were postsynaptic targets of these synapses were identified. We also demonstrate some examples of convergence from other sources onto the neurons that are targets of type II fibers.

\section{MATERIALS AND METHODS}

Methods for our injections and processing appear in previous publications (Brown et al. 1988b; Benson and Brown 1990). All experimental procedures on animals were in accordance with the National Institutes of Health guidelines for the care and use of laboratory animals and were performed under approved protocols at the Massachusetts Eye \& Ear Infirmary. The present study used four adult mice, three of CBA/CaJ strain and one of CD-1 strain. Most of the data were obtained from the CBA/CaJ mice. The mice used in the present study were different mice than those examined in a previous study of type II synapses (Berglund et al. 1996). Mice were anesthetized with intraperitoneal administration of Avertin (5 g of 2,2,2 tribromoethanol dissolved in $395 \mathrm{ml} \mathrm{H}_{2} \mathrm{O}$ with $3 \mathrm{ml}$ amylene hydrate; $0.4 \mathrm{ml}$ per $10 \mathrm{~g}$ body weight). A trans-tympanic surgical approach was used to visualize the round window, which was enlarged by drilling. A 0.15 Minutien insect pin was used to pierce the bone overlying the spiral ganglion in the lower basal turn of the cochlea. A 
pipette containing $30 \%$ horseradish peroxidase (HRP) in $0.1 \mathrm{M}$ Tris buffer ( $\mathrm{pH} 8.6$ ) was advanced into this opening and the HRP was delivered by iontophoresis $(10 \mu \mathrm{A}$ positive current, $10 \mathrm{~s}$ duty cycle, for $10 \mathrm{~min}$ ). After a 24-h survival time, the mice were reanesthetized and sacrificed by intravascular perfusion of saline followed by $0.5 \%$ paraformaldehyde and $1 \%$ glutaraldehyde in $0.1 \mathrm{M}$ cacodylate buffer followed by $0.5 \%$ paraformaldehyde and $3 \%$ glutaraldehyde in buffer. The cochlear nucleus was blocked, embedded in a mixture of gelatin and albumin $(0.5 \%$ and $27 \%$, respectively) that was hardened by the addition of glutaraldehyde ( $2.3 \%$ of total volume), and sectioned (50 $\mu \mathrm{m}$ thickness) on a Vibratome in the sagittal plane. Free-floating sections were processed to reveal the HRP reaction product within the labeled fibers (Fekete et al. 1984; Brown et al. 1988b; Benson and Brown 1990) using diaminobenzidine as the chromogen and adding $1 \%$ dimethylsulfoxide to solutions containing cobalt or diaminobenzidine. After postfixation in $1 \%$ osmium tetroxide for $15 \mathrm{~min}$, the sections were stained en bloc with saturated, filtered uranyl acetate $(1 \mathrm{~h})$, dehydrated with methanol, infiltrated with epoxy, and flatembedded between two transparent sheets of Aclar (Pro Plastics, Wall, NJ).

Sections were first examined using the light microscope. Specimens were selected for further study if they contained a number of darkly labeled type II fibers with distinct swellings yet few labeled olivocochlear branches. Careful camera-lucida drawings were made of the selected sections. On the drawings, different type II fibers were distinguished by colors. Indicated were the fibers' thicknesses and darkness of labeling, the positions and shapes of swellings, and their depths within the section. The few labeled olivocochlear branches were similarly documented. Fiducial marks such as capillaries, red blood cells, neural somata, and the borders of the granule-cell lamina were also indicated. Photomicrographs were taken at a number of different focal planes to provide information that was complementary to the drawings. Then, a portion of the section containing type II fibers was removed and sectioned on an ultramicrotome. During ultrathin sectioning, the tissue block was removed periodically and reexamined in the light microscope. This reexamination was compared with the light microscopic drawing and photomicrographs to indicate which labeled fibers or portions thereof had been sectioned and which remained within the block.

Serial ultrathin sections (70-80 nm thickness) were collected on Formvar-coated slot grids. Without further staining, the sections were then examined in the electron microscope at $2000 \times-11500 \times$ and printed with a final magnification of $6000 \times-30000 \times$.
Guided by the light microscopic results, usually the most darkly labeled type II axons were selected for ultrastructural analysis. We located these type II fibers, followed them through the serial sections to their swellings, and identified synapses and their targets (postsynaptic dendrites or somata). From the electron micrographs, NIH Image and a computerized planimeter were used to measure the areas and diameters of the synaptic terminals. For each type II terminal (and for mossy terminals, see Results) the largest profile containing a synapse was selected for areal measurement. The lengths of apposition between labeled terminals and their targets, and the lengths of the associated postsynaptic densities, were measured in all sections containing the labeled synaptic terminal. We identified the few labeled branches of olivocochlear axons by their thick diameters, more frequent swellings, and orientation in a more mediolateral direction (Brown et al. 1988b; Benson and Brown 1990), and with careful correlation of the light and serial electron microscopic images, we discriminated between labeled fiber types. Unlabeled target dendrites of synapses from type II fibers, as well as other unlabeled dendrites in the electron micrographs, were assigned individual identifiers and followed from section-to-section by alignment with relation to nearby fiducial marks that included other dendrites, axons, somata, and blood vessels. Within the dendrites themselves, we often aligned mitochondria that spanned several sections. In two instances in which small dendrites received labeled type II synapses, they were followed through the serial sections to their somata of origin and then from the somata along other dendrites or axons as far as practicable. The smoothed outlines were assembled to form silhouettes of the neurons (Fig. 5). The positions of unlabeled synaptic terminals onto these neurons were also drawn as the largest profile of each terminal. Labeled and unlabeled synapses in the electron micrographs were assigned individual identifiers. The sizes and shapes of the synaptic vesicles within these unlabeled terminals were judged qualitatively by a trained observer as either large and round, small and round, pleomorphic, or flattened, in accordance with previous studies of cochlear-nucleus terminals (Schwartz and Gulley 1978; Cant and Morest 1979; Benson et al. 1996).

\section{RESULTS}

\section{Light microscopic observations}

Labeled type I and type II auditory nerve fibers traveled centrally from the injection site in the spiral ganglion into the auditory nerve and cochlear nucleus. Single fibers are schematized in Figure 1, al- 


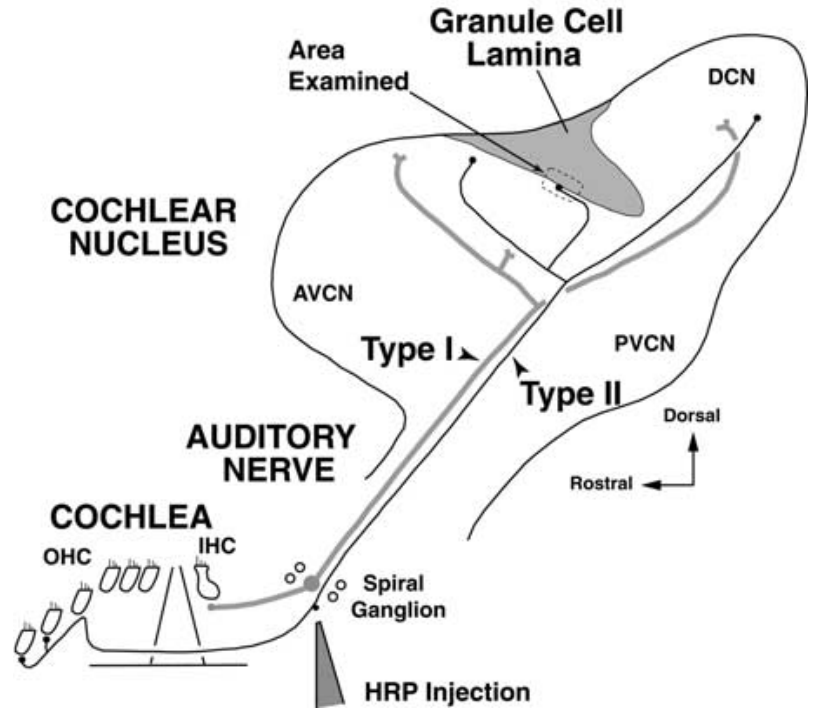

FIG. 1. Schematic showing the site of horseradish peroxidase (HRP) injection to label type II fibers in the spiral ganglion of the cochlea. Auditory nerve fibers are shown peripherally in the cochlea where type II fibers form the afferent innervation of the outer hair cells $(\mathrm{OHC})$ and type I fibers form the afferent innervation of the inner hair cells (IHC). Both fiber types project centrally in the auditory nerve, bifurcate in the cochlear nucleus, and form branches in the anteroventral, posteroventral, and dorsal subdivisions of the cochlear nucleus (AVCN, PVCN, and DCN). Dividing the VCN from the DCN is the granule-cell lamina, a region of termination for many type II fibers. Type II fibers in the lamina were examined in the approximate location indicated by the dashed box. The figure orientation is approximately the sagittal plane (see compass indicating dorsal toward the top of the figure). In successive figures, the orientation is reversed (dorsal toward the bottom of the figure) in order to be consistent with our previous work (Brown et al. 1988b; Benson and Brown 1990; Benson et al. 1996).

though each of our HRP injections resulted in the labeling of hundreds of type I fibers and dozens of type II fibers. Labeled type II fibers are recognized by their (1) characteristic morphology-uniformly thin $(<0.7 \mu \mathrm{m})$ and lacking obvious nodes of Ranvier, and (2) site of termination in the granule-cell lamina of the cochlear nucleus (Fig. 1). Fibers with these characteristics have been traced back to parent fibers and cell bodies of origin and confirmed to be type II in previous studies (Brown et al. 1988a; Brown and Ledwith 1990; Berglund and Brown 1994; Berglund et al. 1996). These studies also suggest that the complete extent of the type II projection into the cochlear nucleus is revealed with HRP labeling. That is, in the most darkly labeled fibers, such as for most of those of the present study, there are no indications of fading of the reaction product. The portions of type II fibers selected for examination in the electron microscope were within the granule-cell lamina and its narrow, edge region at the border of the magnocellular core (Fig. 1). This region is within the anteroventral subdivision of the cochlear nucleus

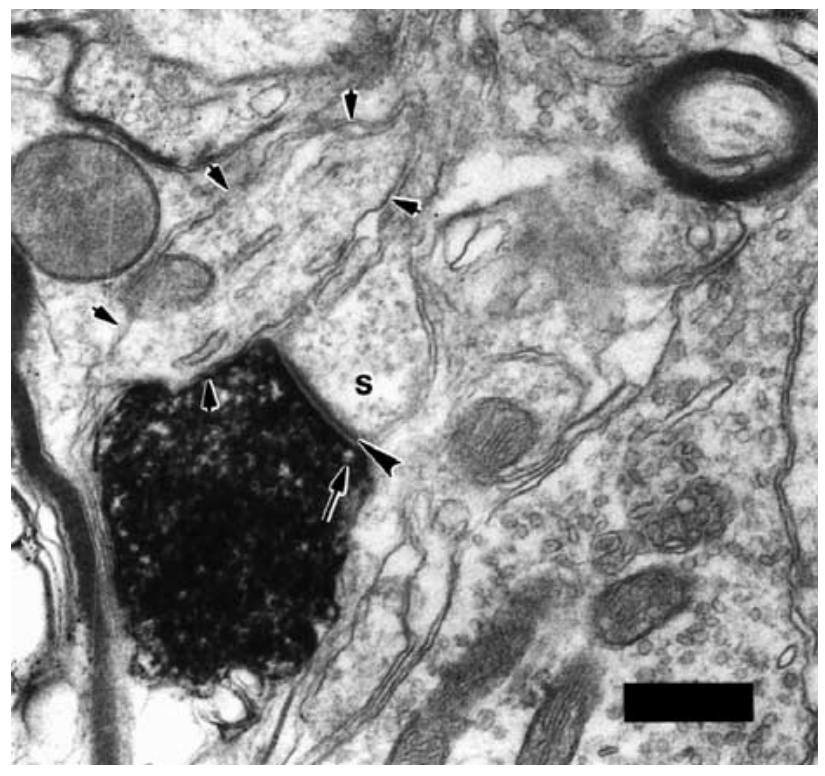

FIG. 2. Electron micrograph of a labeled type II terminal swelling forming a synapse on a dendritic spine (s). The specialization demonstrates the morphological criteria for synapses: synaptic vesicles (one denoted by arrow); synaptic cleft and postsynaptic density (large arrowhead). In this example the density is darker and thicker than in most other type II synapses (Fig. 3). The dense HRP reaction product typically obscures most morphology in the swelling. The dendritic spine was connected in other sections of the series to a "small dendrite" (outlined by small arrows; also illustrated in Fig. 3A). Scale bar $=0.5 \mu \mathrm{m}$. The scale bar is positioned upon an unlabeled terminal that contains pleomorphic vesicles.

(AVCN) and is just dorsal and rostral to the bifurcations of the labeled auditory nerve fibers. The border region contained terminations of labeled type I fibers, which formed a distinct edge within the limits of the core. Granule cells of the lamina also formed a well-defined edge. Both of these edges, as well as the labeled type II fibers that ran in between them, were contained within the approximately $100-\mu \mathrm{m}$ strip of tissue that we examined. Our material also contained a few labeled branches of olivocochlear axons.

\section{Synapses from type II swellings}

When examined in the electron microscope, sections through labeled type II swellings demonstrated characteristics typical of morphologic synapses (Fig. 2). Our criteria for a synapse consisted of three characteristics. First, the labeled terminal must contain synaptic vesicles and at least one of them must be located within a vesicle-width from the synaptic area. Such vesicles were sparse in type II terminals, possibly because they were obscured by the reaction product. However, vesicles were sparse even in terminals from one fiber that was classified in the light microscope as "faintly labeled" (Figs. 2 and 3A). As reported previously, the vesicles in the type II terminals were 

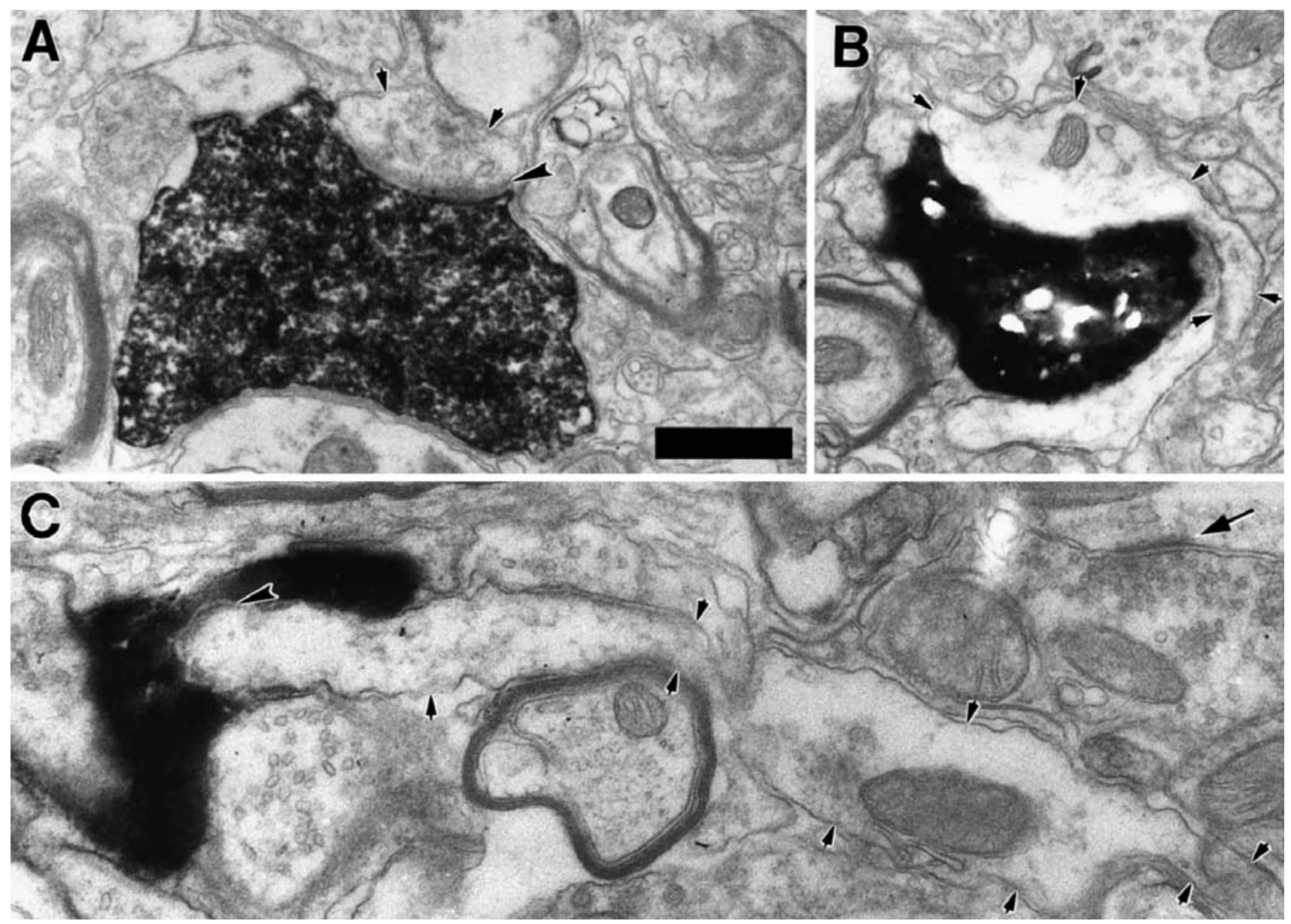

FIG. 3. Electron micrographs of three small dendrites (delineated with small arrowheads) receiving synapses from type II fibers. In panels $\mathbf{A}$ and $\mathbf{C}$ the postsynaptic density is indicated with large arrowheads, but in panel $\mathbf{B}$ the labeled terminal was synaptic in other sections. In panel $\mathbf{A}$, the small dendrite could not be traced to its soma of origin, but it received a second synapse from the same labeled terminal onto a spine in a nearby section (Fig. 2). The small dendrite of panel $\mathbf{B}$ became much larger in nearby sections, as if swollen relative to other parts of the dendrite. This dendrite was

smaller than those in type I terminals (Ryugo et al. 1991; Berglund et al. 1996).

The second characteristic necessary for a synapse was the presence of a postsynaptic density within the postsynaptic element. In synaptic terminals from type II fibers, the average length of the densities was $0.7 \mu \mathrm{m}$ (range: $0.4-0.9 \mu \mathrm{m}$, measured in the section containing the longest density) for 7 synapses. Much of the apposition between presynaptic terminal and postsynaptic element had a density: on average the ratio of apposition/density lengths was $36 \%$. In contrast, synapses from three type I fibers were shorter (avg: $0.3 \mu \mathrm{m}$, range: $0.2-0.6 \mu \mathrm{m}$ ) and had lower ratios (18\%) of synaptic apposition, as measured for 57 synapses from 3 modified endbulbs of two of the experimental animals. These data confirm previous studies of the core of the cochlear nucleus (Ryugo followed through serial sections to the soma of a small cell (Figs. 4, $5 \mathrm{~A})$. The small dendrite in panel $\mathbf{C}$ is sectioned relatively longitudinally and is seemingly engulfed by the labeled type II terminal, a swelling found at a branch point of the fiber. The dendrite in $\mathbf{C}$ was also connected, through serial sections, to a small cell (Fig. 5B). Arrow denotes density of a synapse formed by an unlabeled terminal containing small round vesicles. Scale bar in $\mathbf{A}=0.5 \mu \mathrm{m}$ and also applies to $\mathbf{B}$ and $\mathbf{C}$.

et al. 1991; Berglund et al. 1996). None of the type II synapses of the present study had discontinuous or perforated densities nor did any obviously contain signs of flocculent neuronal degeneration (Berglund et al. 1996; Benson et al. 1996), although this could have been obscured by reaction product.

The final characteristic necessary for a synapse was the presence of a clear synaptic cleft of relatively uniform width between pre- and postsynaptic membranes, as compared with the usually narrower space between parajunctional membranes. Nonsynaptic swellings lacked synaptic clefts and densities and thus did not meet our criteria.

Of a total of 27 swellings examined in their entirety in serial sections, $19(70 \%)$ formed at least one synapse. Most synaptic swellings formed a single synapse but three of them formed two separate syn- 
apses. When two separate synapses were formed, the postsynaptic elements were always common for the two synapses. Our database came from four different mice in which we examined 7 labeled type II axon segments. Swellings were defined as portions of the type II fiber that appeared thicker than twice the diameter of the fiber when examined in the light microscope (Brown and Ledwith 1990). Most of the swellings examined were en passant swellings (21 examined, of which 14 formed synapses), a few were at branch points (3 examined of which 2 formed synapses), and a few were axon terminals (3 examined, all of which formed synapses). Synaptic swellings were generally small. For the 19 synaptic swellings measured with NIH Image, the average silhouette area was $0.65 \mu \mathrm{m}^{2}$ (range: $0.16-1.81 \mu \mathrm{m}^{2}$ ) as measured in the electron micrographs containing the synapses. The lengths of the major and minor axes of the best-fitting ellipse as computed by NIH Image averaged $1.11 \mu \mathrm{m}$ and $0.69 \mu \mathrm{m}$, respectively.

Previously, it was shown that most of the swellings of type II fibers in the cochlear nucleus core are ellipsoidal in shape (Brown and Ledwith 1990) and often do not give rise to synapses (Ryugo et al. 1991; Berglund et al. 1996). In the present study, most of the swellings examined for synapses were nonellipsoidal when viewed with the light microscope, having angular edges, complex shapes, or being formed at branch points. In the electron micrographs, the nonellipsoidal shapes can be appreciated from the relatively straight appositions that some swellings make with their postsynaptic elements (Fig. 2). However, there was not a one-to-one correlation between swelling shape and formation of synapses. For example, some swellings judged to be nonellipsoidal in the light microscope failed to form synapses when examined in the electron microscope. Conversely, in a few cases synapses were formed by ellipsoidal swellings. Finally, no synapses were found on portions of the type II fibers between swellings. All portions of the type II fibers examined were devoid of myelin.

\section{Small dendrites were the most common targets}

Dendrites, especially small dendrites of diameter 0.5$1 \mu \mathrm{m}$, were the most common postsynaptic targets of synapses from type II axons (Fig. 3). Of the 19 synaptic swellings studied, 12 formed their synapses onto small dendrites (Table 1). The small dendrites could be traced through the serial sections by aligning fiducial marks including other dendrites, axons, somata, blood vessels, and mitochondria within the dendrites themselves. These dendrites were gradually tapering but in a few cases they formed enlargements or swellings. Some of them were smooth but others had infrequent spines and six of the type II synapses

\section{TABLE 1}

Postsynaptic targets

Number of synapses ${ }^{a}$

Synapses onto dendrites

Small dendrites/spines, including

two traced to small cells

Large dendrites

Synapses onto cell bodies

Presumed multipolar cells

Presumed globular bushy cell

4

1

${ }^{a}$ Instances of multiple synapses from 1 swelling on same target count as 1 .

were found on these spines (Fig. 2). Small dendrites appeared most often in cross section in our material, indicating a mediolateral orientation. In general, they had a course parallel to the lamina border, usually not veering off into either the granule-cell lamina or the core of the ventral cochlear nucleus. Tracing small dendrites through the serial sections was relatively straightforward, but most (10 out of 12) could not be traced all the way to somata. This was because they exited the $50-\mu \mathrm{m}$ thick tissue section or, for the thinnest profiles, because of ambiguities within the neuropil. Nevertheless, two of the small dendrites were followed through the serial sections without ambiguity to their cell bodies. The dendrite illustrated in Figure 3B was traced through 43 serial sections to its soma and the dendrite illustrated in Figure 3C was traced through 21 serial sections to its soma. Additional serial sections were examined to document these somata in their entirety and parts of their other dendrites.

The two somata of origin giving rise to the small dendrites were both cochlear-nucleus "small cells" (Osen 1969; Hackney and Osen 1985). One of these small cells and nearby granule cells are shown in Figure 4, and silhouettes of both small cells are shown in Figure 5. The somata of these cells were maximally about $9 \mu \mathrm{m}$ in diameter, larger than granule cells that are maximally about $6 \mu \mathrm{m}$ in diameter, but smaller than most principal cells of the cochlear nucleus. Like granule cells, the small cells had nuclei with chromatin aggregates, but unlike granule cells, the small-cell nuclei were indented and had one or more nucleoli. Both small cells had three dendrites and the initial portions of the axons were identified. In both small cells, the dendrites that received the type II synapses were small but had swellings or enlargements approximately four times the diameter of the dendrite (marked by "e" on Fig. 5). These enlargements contained several mitochondria and other organelles and thus did not appear to be artifactual. In one case the synapse was onto the enlarged section of the dendrite (Fig. 5A). In the other 


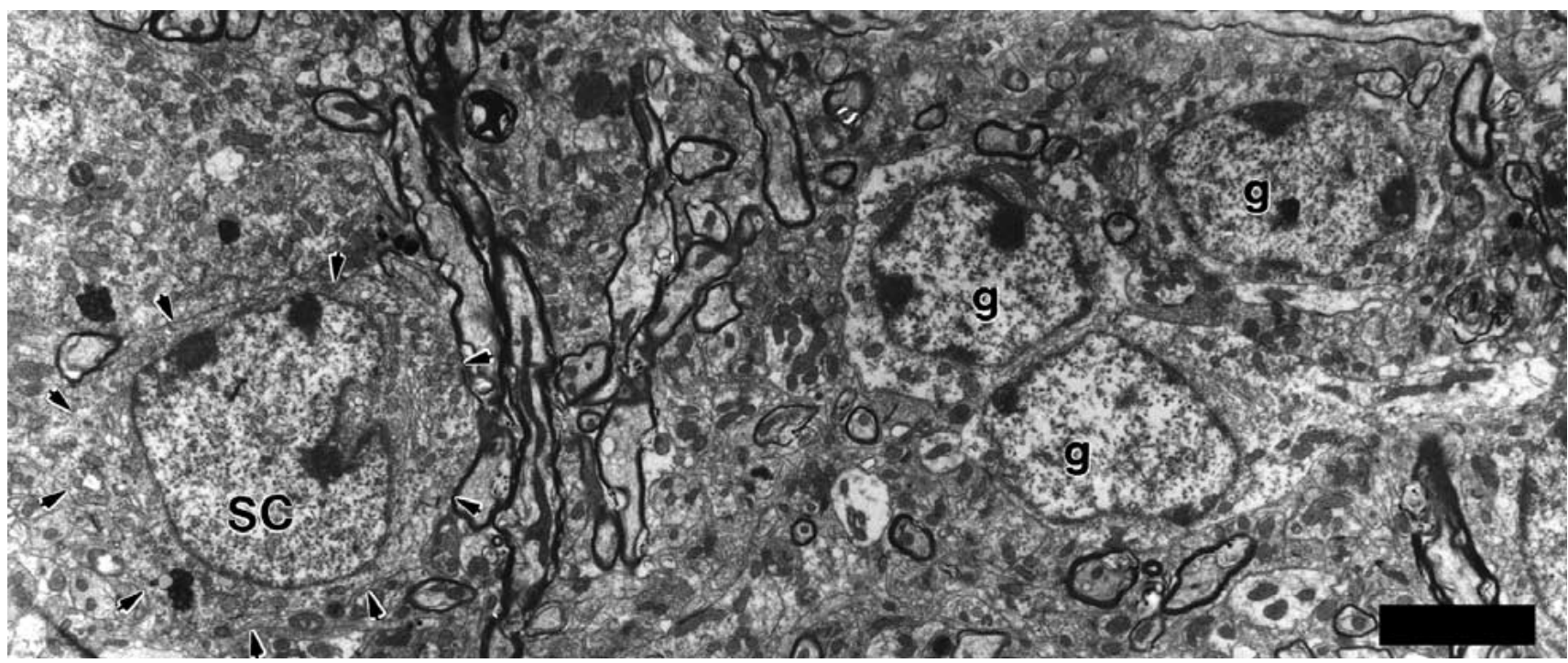

FIG. 4. Electron micrograph of a small cell (SC) and a nearby cluster of granule cells (g). The small cell received, on its small dendrite, a synapse from an en passant swelling of a type II axon (Figs. 3B, 5A). Like granule cells, the small cell has chromatin ag-

case, the synapse was distal to the enlargement (Fig. 5B). Both of the small cells had one dendrite that was thicker than the other two. This dendrite did not form enlargements but did form at least one spine. The dendrites that could be reconstructed to some extent were those that were generally parallel to our plane of section, whereas other dendrites could not be reconstructed.

Both small cells were examined, on the entire cell body and proximal dendrites, for the presence of synapses from unlabeled terminals (Fig. 5). One small cell (Fig. 5A) received 6 unlabeled synaptic terminals onto its cell body and 8 unlabeled synaptic terminals onto its proximal dendrites, including two that formed synapses onto spines. The other small cell (Fig. 5B) received no somatic synapses but 7 unlabeled synaptic terminals onto a proximal dendrite, including one onto a spine. The terminals onto the two small cells can be classified according to the size and shape of their synaptic vesicles. Using the accepted classification scheme (Schwartz and Gulley 1978; Cant and Morest 1979; Benson et al. 1996), most of the synaptic terminals $(n=18)$ had vesicles that were small and round (Fig. 5, Sm Rnd). A few of the terminals, only 3 that were all onto the cell shown in Figure 5A, had vesicles that were pleomorphic (e.g., lower right of Fig. 2). All of the synapses were examined for the presence of postsynaptic bodies, which are small round structures (e.g., Fig. 8C) that appear adjacent to some synapses formed by olivocochlear branches in the granule-cell lamina (Benson and Brown 1990). Postsynaptic bodies were found at two of the synapses with small round vesicles, one onto each of the small gregates in its nucleus, but it is larger than the granule cells and has a distinctive nuclear fold. Its perikaryal organelles are more densely packed, thus its cytoplasm appears darker than that of the granule cells. Scale bar $=5 \mu \mathrm{m}$.

cells (Fig. 5, Sm Rnd w/psbs). These synapses also had thicker and more obvious postsynaptic densities than those typically associated with type II synapses. Overall, the major input to the small cells consisted of synaptic terminals with small round vesicles, perhaps some of which were from olivocochlear branches or type II fibers that were not labeled by our injections. Since these terminals were not labeled, though, it is not possible to determine their origin.

Round vesicles were also the predominant type seen in unlabeled terminals in the neuropil of the lamina in the immediate vicinity of labeled type II fibers (Fig. 3C). A total of 388 synapses in two mice were studied. The great majority $(n=360)$ had small round vesicles and the remainder $(n=28)$ had pleomorphic vesicles (Fig. 2). Nine of the terminals with round vesicles had associated postsynaptic bodies. Also similar to most type II targets, small dendrites or their spines in the neuropil were the most common target of these synapses (268 of 388 synapses). However, a difference from the type II results was that the neuropil contained many unlabeled mossy terminals (forming 86 of 388 synapses) as described previously (Mugnaini et al. 1980b; Weedman et al. 1996). These terminals are larger than type II terminals. For 12 mossy terminals, the average silhouette area was $2.60 \mu \mathrm{m}^{2}$ (range: $1.49-4.06 \mu \mathrm{m}^{2}$ ) and the lengths of the major and minor axes of their best-fitting ellipses averaged $2.13 \mu \mathrm{m}$ and $1.45 \mu \mathrm{m}$, respectively. Their synaptic vesicles were small and round but there were never associated postsynaptic bodies. The mossy terminal is centrally positioned within a glomerulus that contains numerous dendrites likely arising from 

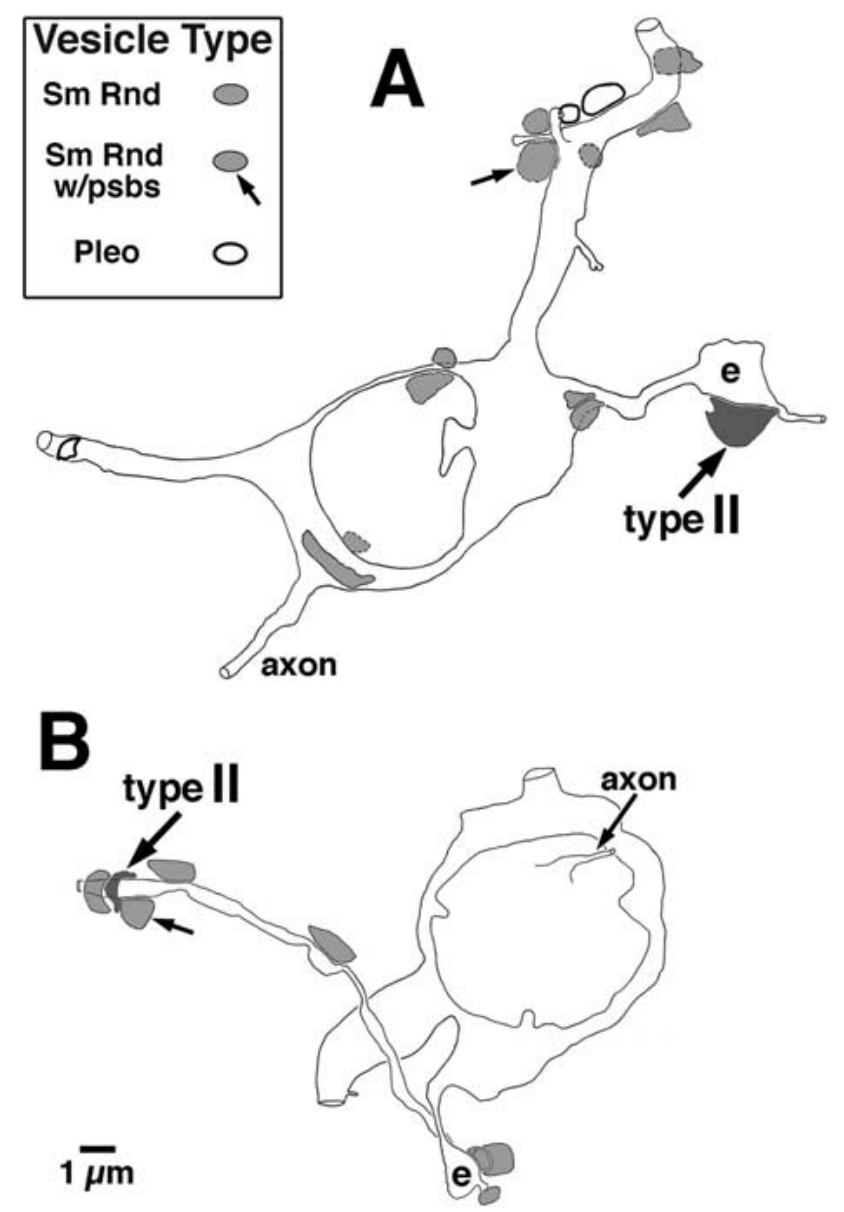

FIG. 5. Silhouettes of two small cells that received synapses from type II fibers onto their small dendrites. The dark shading shows the positions of the labeled type II terminals that formed the synapses (synapse for the cell of panel A is shown in Fig. 3B; synapse for the cell of panel $\mathbf{B}$ is shown in Fig. 3C). Also indicated are the positions of other, unlabeled terminals that formed synapses onto these small cells, coded according to the shape of their synaptic vesicles (Sm Rnd: small and round; Pleo: pleomorphic) (Schwartz and Gulley 1978; Cant and Morest 1979; Benson et al. 1996), as well as the presence of postsynaptic bodies ( $\mathrm{Sm}$ Rnd w/psbs) in the postsynaptic element. The approximate sizes of these terminals on the figure are taken as the maximal silhouette area observed in the series of sections through the terminals. Each cell received synaptic input onto a dendritic enlargement (e). The cell in panel A was pictured in Figure 4.

granule cells. The terminal forms numerous synapses onto the dendrites but not onto hairlike processes of the dendrites that sometimes penetrate into the terminal. These findings are very different from the type II results because the type II swellings in the present study neither formed mossy terminals nor did they synapse on granule-cell dendrites in glomeruli. Additionally, a few of the unlabeled neuropil synapses were onto somata or proximal dendrites of granule cells $(n=4)$, small cell somata $(n=4)$, or unidentified targets $(n=2)$. Finally, large dendrites were postsynaptic elements in some cases $(n=24)$, although these were never participants in synaptic glomeruli.
Multipolar cells and other neurons were less common targets

A minority of the synapses from labeled type II fibers were axosomatic or upon somatic specializations, and four of these targets were neurons likely to be multipolar cells (Table 1). Two examples of such cells are seen in Figure 6 and two other large cells of similar morphology received synapses in the same mouse. Their proximity to granule cells can be appreciated from the figure. These neurons had somata with large diameters (about $23 \mu \mathrm{m}$ ) and were somewhat fusiform in shape (Fig. 6). Much of each cell body was examined in the electron microscope. Subsurface cisternae were visible in all four somata. The cell membranes were smooth except for rare spines and somatic appendages. In one cell, the type II synapse appeared on a "bootlike" appendage that is outlined by arrowheads in Figure 6 . In two other cells, one of which received two type II synapses, the synapses were onto small "mesalike" protuberances. In the fourth cell, the synapse was found on an otherwise nonspecialized cell membrane. The somatic membranes of these cells received only infrequent synapses from other unlabeled terminals. One of these unlabeled synaptic terminals had the appearance of flocculent neuronal degeneration as described by Benson et al. (1996). Three of the four somata gave rise to at least two dendrites that had thick diameters $(1.5-3 \mu \mathrm{m})$; these dendrites tapered gradually from the somata and took a course roughly parallel to the granule-cell lamina. The overall morphology of these neurons suggests that they are multipolar cells (Osen 1969; Cant 1981).

Another large neuron that received an axosomatic synapse is pictured in Figure 7. Although this neuron was not conclusively identified, it is probably not a multipolar cell. This cell was located within $20 \mu \mathrm{m}$ of the border of the granule-cell lamina. In serial sections, about $40 \%$ of this neuron's soma was examined, assuming that it is an oblate spheroid. The major diameter of the cell is $26 \mu \mathrm{m}$. The cell has an extensive Golgi apparatus. A large core-directed dendrite arises rather abruptly from the cell body rather than tapering as for the multipolar cells described above. It was the only dendrite observed. The neuron's dendrite received several terminals, including one that was labeled. Another labeled axosomatic terminal is visible (asterisk on Fig. 7). The origin of that terminal could not be determined but within our photomicrographs and serial sections it connected with other axosomatic contacts. These connected terminals each formed one or more punctate synapses characteristic of type I auditory nerve fibers. Together, these labeled terminals form a modified endbulb (Rouiller et al. 1986). Taken together, the morphology of this cell, 


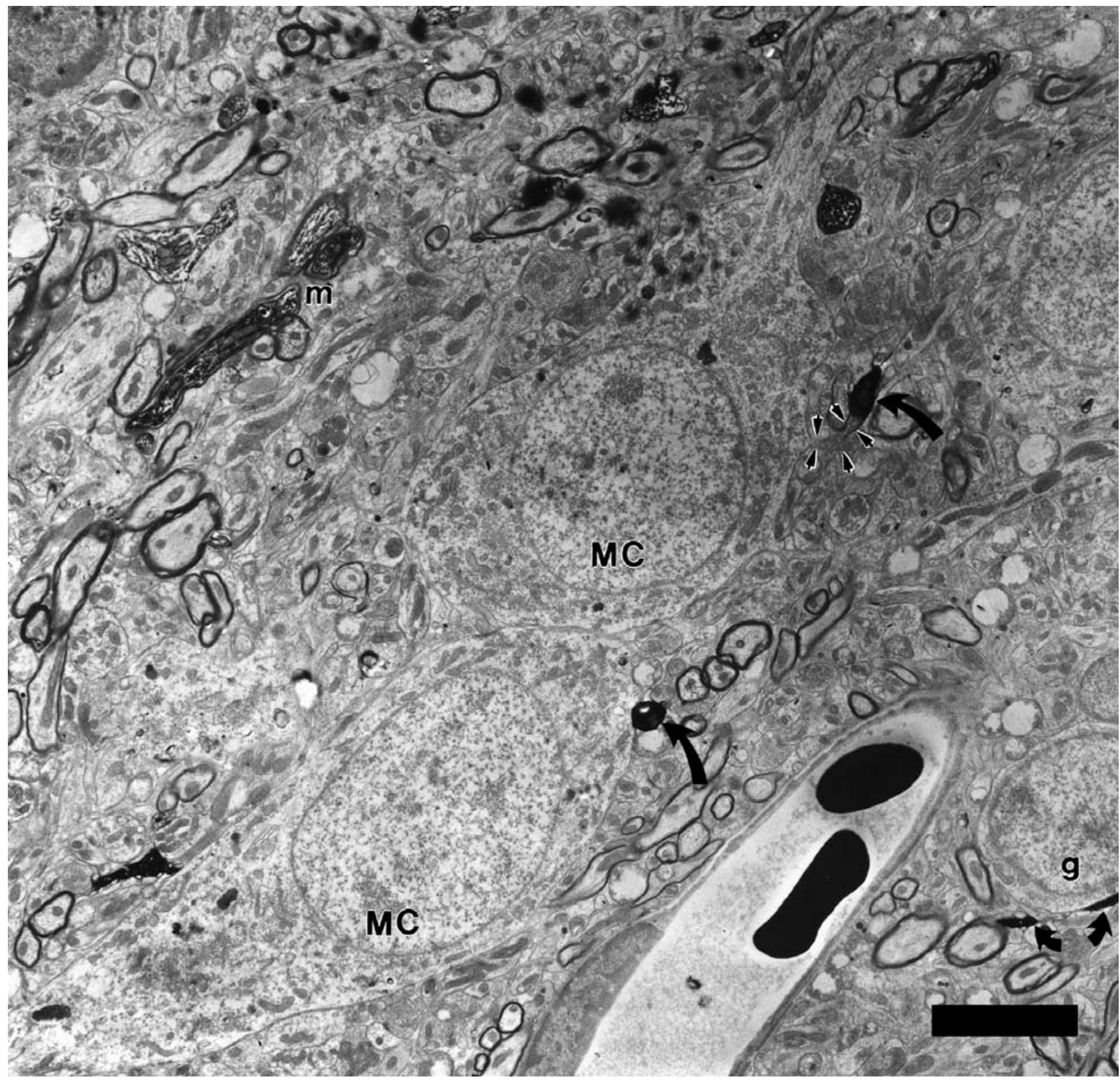

FIG. 6. Two presumed multipolar cells $(\mathrm{MC})$ that received axosomatic synapses from labeled type II terminals. Swellings of the labeled type II fiber are indicated by two black, curved arrows. The swelling at the lower middle of the micrograph is a terminal swelling of the type II fiber and the swelling at the upper middle of the micrograph is a branch point swelling of the same type II fiber. This latter swelling synapses with a bootlike somatic appendage of the

along with its receiving a modified endbulb, suggests that it is a globular bushy cell.

The postsynaptic targets of labeled type II fibers also included two examples of large dendrites (diameter $>2 \mu \mathrm{m}$ ) (Table 1) that could not be traced to their somata of origin. The large dendrites were oriented parallel to the edge of the granule-cell lamina. One of these large dendrites is seen in Figure 8A, B upper cell (outlined by small arrows). The cells are on the border of the lamina; a granule cell $(\mathrm{g})$ is visible at lower right. Also at lower right, curving under the granule cell, is another labeled type II fiber (small arrows) illustrating the typical thin diameter of these fibers. Thicker-labeled myelinated fibers $(\mathrm{m})$ and terminals from type I fibers within the core of the cochlear nucleus are visible at upper left. Scale bar $=5 \mu \mathrm{m}$.

in the sections in which it receives the synapse from the labeled type II fiber. This large dendrite was also contacted by two unlabeled terminals that formed synapses with postsynaptic bodies (e.g., Fig. 8C), suggesting input from olivocochlear branches (Benson and Brown 1990). Indeed, the morphology of these large dendrites is similar to those large dendrites that are the principal targets of 


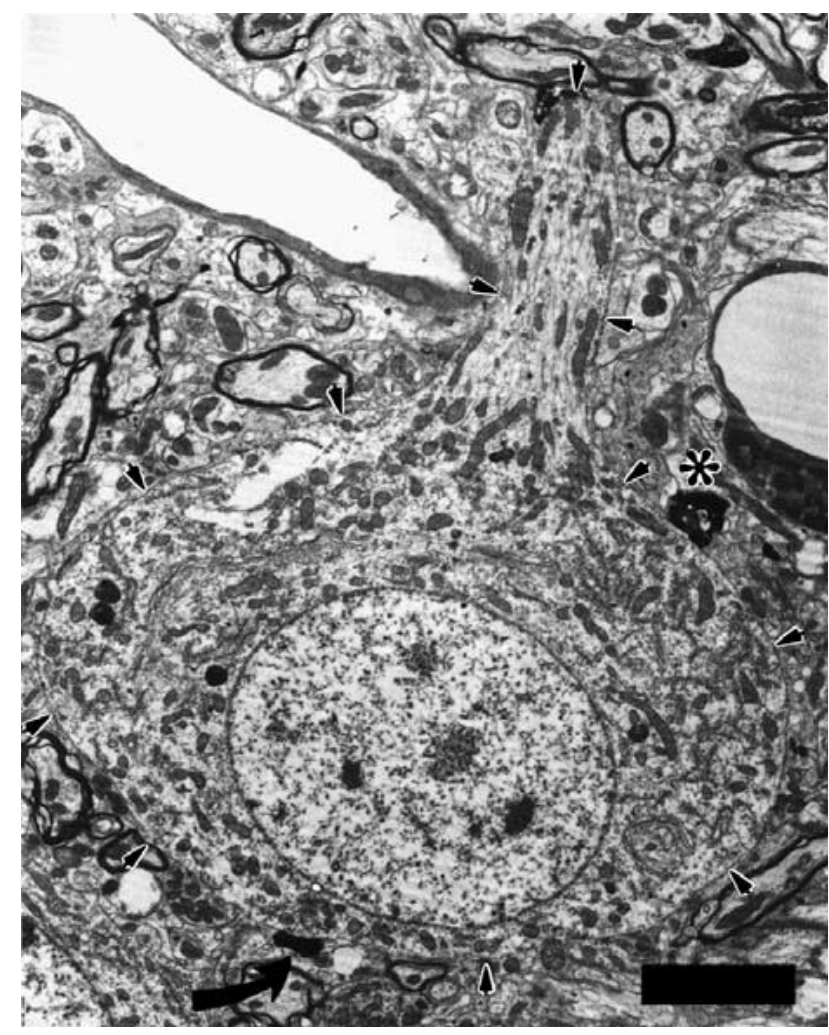

FIG. 7. Electron micrograph of a large neuron (outlined by arrows) that received two axosomatic synapses from a terminal swelling of a type II fiber. The neuron was located at the border of the granule-cell lamina, and it gave off a large dendrite directed toward the core of the ventral cochlear nucleus. This dendrite receives several terminals, one of which is darkened with HRP label. Another labeled axosomatic terminal is visible just beneath the asterisk. The origin of that terminal could not be determined unambiguously, but it connected with other axosomatic terminals that also formed punctate synapses with the neuron. Together, the terminals comprise a modified endbulb, suggesting that this neuron is a globular bushy cell that receives input from both type I and type II auditory nerve fibers. Scale bar $=5 \mu \mathrm{m}$.

olivocochlear branches in the lamina (Benson and Brown 1990).

A summary of the synaptic targets of type II fibers is seen in Figure 9. The targets are mainly small dendrites, at least some of which emanate from small cells, and an additional two untraced large dendrites. Targets of axosomatic synapses were presumed mutipolar cells and a presumed globular bushy cell. Figure 9 also summarizes the other, unlabeled inputs to the type II targets. These inputs are identified by the size and shape of their synaptic vesicles, and their potential sources are listed on the figure.

\section{DISCUSSION}

Postsynaptic targets of type II fibers

The high percentage of synaptic swellings of type II auditory nerve fibers enabled us to determine postsynaptic targets in the granule-cell lamina at its border with the magnocellular core of the ventral cochlear nucleus. Although the number of swellings that were examined was not large $(n=27)$, the proportion that formed synapses was $70 \%$. This is a much higher proportion than found previously in other regions of the cochlear nucleus. In contrast, in the nerve root, only about $10 \%$ of the swellings are synaptic (Ryugo et al. 1991; Hurd et al. 1999). In a survey of mainly core regions of the ventral cochlear nucleus, only $18 \%$ of the swellings were synaptic (Berglund et al. 1996). When coupled with the fact that type II fibers from all cochlear turns give off branches to the granule-cell lamina (Berglund and Brown 1994), these data suggest that the lamina and its border are very important cochlear-nucleus areas for synaptic input from type II fibers. Furthermore, since type I fibers rarely project into the lamina (Brown and Ledwith 1990), type II input may be the sole auditory nerve input to this region.

A "big picture" view of type II postsynaptic targets is diversity. This view emerges if the sample of targets from the present study is considered along with targets from an earlier study of different mice (Berglund et al. 1996). Even with its narrow focus on the granule-cell lamina, the present study demonstrated that type II targets include small cells, multipolar cells, and another large cell likely to be a globular bushy cell (Table 1, Fig. 9). Previously identified targets of a broad regional study (Berglund et al. 1996) included a spherical bushy cell and granule cells. The latter cell type was implicated because one terminal comprised the center of a glomerulus (Mugnaini et al. 1980b). This seems a rare occurrence since no labeled mossy terminals were observed in the present study though the type II fibers ran among neuropil containing many mossy terminals. Mossy terminals arise from sources as distant as the auditory cortex (Weedman and Ryugo 1996). Type II targets are potentially as diverse as those of type I auditory nerve fibers, which make contact with at least a half-dozen different types of cochlear-nucleus neurons (Rouiller et al. 1986; Cant 1992). Overall, we now know that even in noncore regions of the cochlear nucleus, type II input is received by diverse neurons that include both principal neurons and other smaller neurons. This diversity suggests that type II neurons can affect targets involved in a variety of functional processes.

The most common postsynaptic targets of type II fibers in the lamina were small-diameter dendrites. In two cases the neurons giving rise to the dendrites were identified as small cells, and it may be that small cells are the predominant type II target. It is also possible, though, that some of the small dendrites emanate from granule cells or are the tips of tapering dendrites of large multipolar cells. The small cells are 


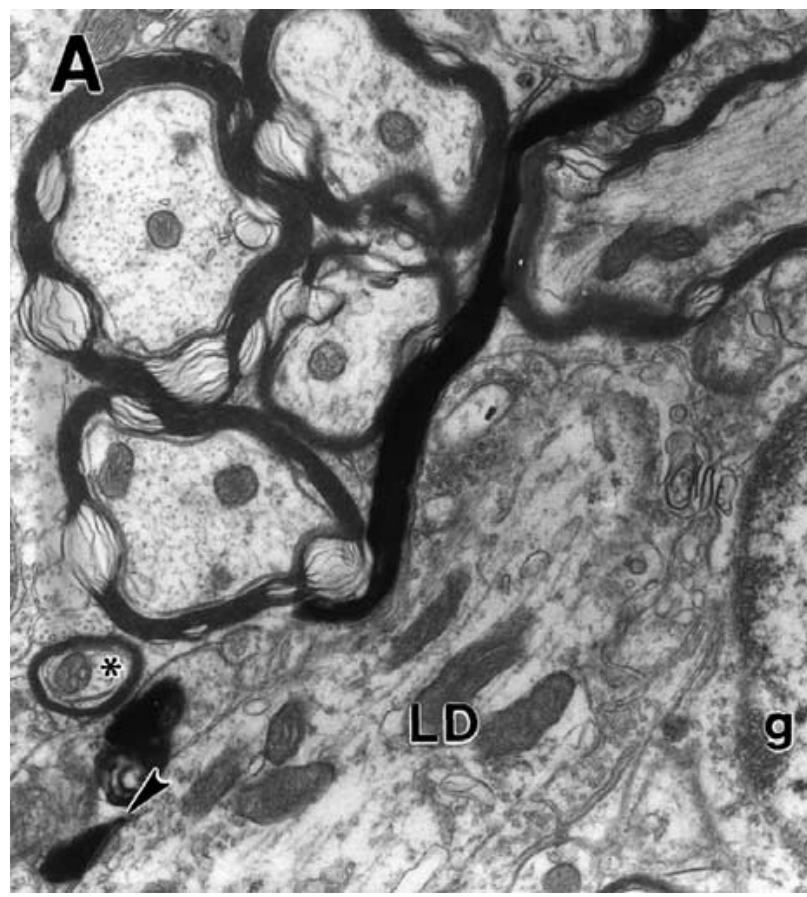

FIG. 8. Large dendrite (LD) that received a synapse (arrowheads in panels $\mathbf{A}$ and $\mathbf{B}$ ) from a type II axon. The dendrite could not be traced to its soma, but its large diameter makes it distinct from the small dendrites of Figure 3. C The same large dendrite, in another section, also receives an unlabeled synapse with a robust postsynaptic den-

likely to be a particular subset of a rather heterogeneous cell group (Cant 1993; Hutson and Morest 1996; Weedman and Ryugo 1996). Although the small cells of the present study cannot be further identified, it does not seem likely that they are Golgi cells, mitt cells, unipolar brush cells, or chestnut cells. Golgi-cell dendrites have numerous appendages giving them a "hairy" appearance (Mugnaini et al. 1980b). Mitt cells or unipolar brush cells have only a single, very thick dendrite (Floris et al. 1994; Hutson and Morest 1996; Weedman et al. 1996). Chestnut cell somata have scalloped cell membranes (Weedman et al. 1996). By contrast, our small cells had smooth membranes and each had multiple dendrites that were only sparsely spined. Both of our cells, though, did have one dendrite that was thicker than the other dendrites at least close to the cell body. Since their dendrites were generally tapering, these small cells seem to be different than a "varicosedendrite" small cell (Benson and Brown 1990), which had two dendrites both with distinctive hourglass-like varicosities interspersed with narrowings containing bundles of microtubules. Since only one of our target small cells received synaptic terminals onto its cell body, the presence of somatic input does not appear to be an invariable marker of such cells. The two small cells studied here were restricted to a particular cochlear-nucleus region (the lamina bor-

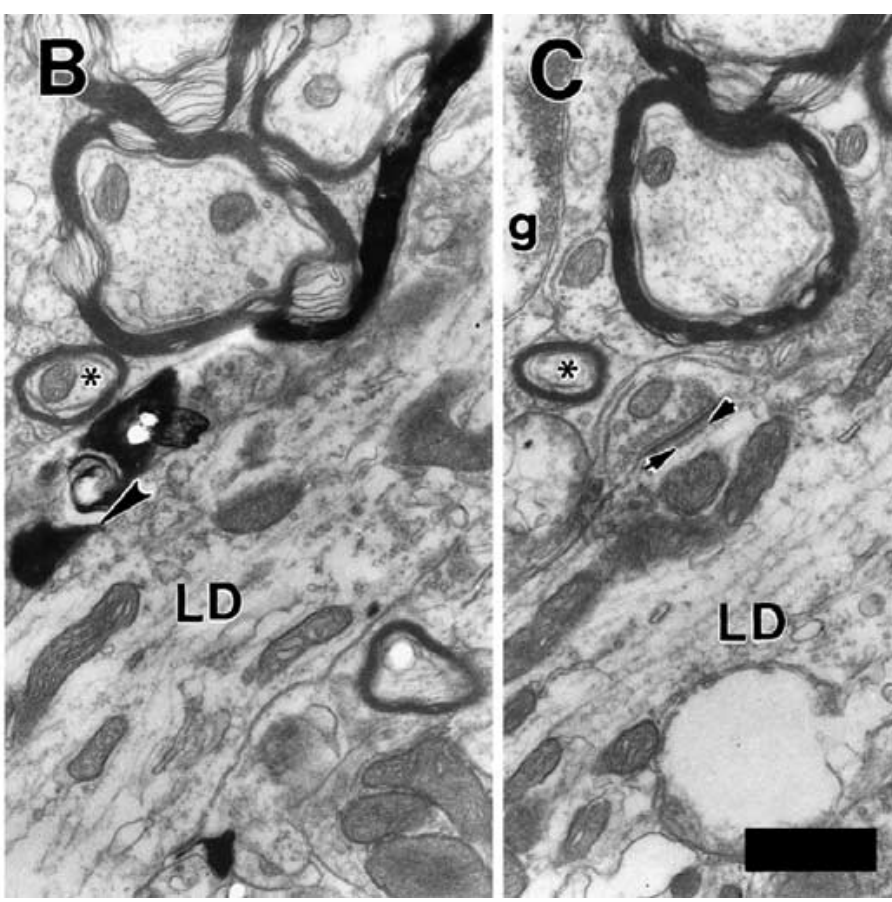

sity and with four postsynaptic bodies (between arrows), which is a synapse typical of those formed by medial olivocochlear branches (see text). Part of a granule cell ( $\mathrm{g}$ ) is indicated. In all panels, the asterisk denotes an axon with a relatively constant orientation relative to the large dendrite. Scale bar $=1 \mu \mathrm{m}$.

der). Small cells form an incomplete "cap" at the dorsal edge of the ventral cochlear nucleus of the cat but not obviously so in the area examined in the present study of the mouse. Rather, in mouse the large cells border the granule-cell lamina (Fig. 6) and small cells are intermingled at that border.

The present study is the first to demonstrate that type II fibers form axosomatic synapses onto neurons likely to be multipolar cells. These cells may also be the source of the large dendrites that were also type II targets. Multipolar cells are a large and heterogeneous group of neurons. Work on the subtypes of multipolar cells is an active area and there appear to be species differences. Subtypes are defined on the basis of the degree of somatic input received; the fact that the target multipolar cells of the present study had few somatic terminals suggests they are like "type I" multipolar cells of the cat (Cant 1981). The target multipolar cells' position along the edge of the granule-cell lamina suggests that they might correspond to "marginal cells" of the rat (Doucet and Ryugo 1997). In mouse, the species used in the present studies, two subtypes of multipolar cells have been defined on the basis of axonal projection. The D-stellate cells have axons that proceed in a dorsal direction; these neurons also have dendrites associated with the granule-cell region (Oertel et al. 1990) as do the multipolar cells/large dendrites of the 
TARGETS OF TYPE II FIBERS
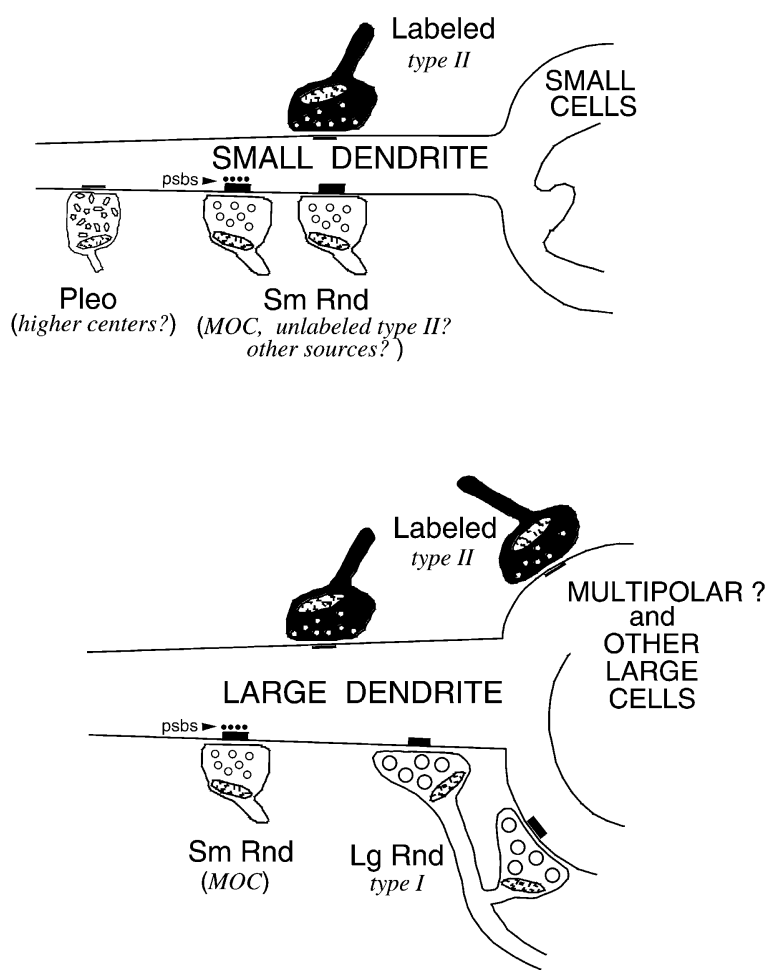

FIG. 9. Summary of the synaptic targets of type II fibers observed in the present study. Most of the targets are small dendrites, at least some of which emanate from cochlear-nucleus small cells. Some targets are cell bodies of presumed multipolar cells. Occasional targets were large dendrites and presumed bushy cells. On the figure, labeled type II synaptic terminals are shaded in black and unlabeled synaptic terminals are unshaded. The unlabeled terminals are classified by the size and shape of their synaptic vesicles (abbreviations as in Fig. 5). Their potential sources are listed in italics.

present study. In the present study, the multipolar cells' fusiform rather than stellate shape is somewhat atypical (Osen 1969; Cant 1981). Also, the extent to which their uncommon mesalike and bootlike appendages correspond to the spines seen on cat multipolar cells is not clear (Cant 1981). Given species differences, although it is likely that our cells correspond to multipolar cells, their characterization as a particular subtype awaits future study.

\section{Convergence of type II and olivocochlear input onto small cells}

Convergence of type II and olivocochlear input onto certain cochlear-nucleus neurons is suggested by our results. We have previously demonstrated topological convergence of these two fiber types into the granulecell lamina (Brown et al. 1988b; Brown and Ledwith 1990). Now, convergence onto single neurons is suggested by our finding that the two small cells that were postsynaptic targets of type II synapses also re- ceived unlabeled synapses with postsynaptic bodies. Synapses with such postsynaptic bodies are found at about one-fourth of the synapses produced by olivocochlear branches to the cochlear nucleus (Benson and Brown 1990). Postsynaptic bodies have not been reported at synapses from other identified sources, although other sources cannot be completely excluded. These observations are suggestive of type II and olivocochlear input onto the same cochlear-nucleus neurons, as summarized in Figure 9 for both the small cell dendrites as well as the large dendrite. The round shape of the vesicles found in both olivocochlear and type II terminals suggests that both inputs would cause their small-cell targets to be excited (Uchizono 1965). Given the expected slow conduction time of type II fibers (Brown 1993; Brown 1994) and the 5-10-ms minimum latency of the medial olivocochlear reflex pathway (Robertson and Gummer 1985; Liberman and Brown 1986), temporal convergence of these two types of inputs is possible. The olivocochlear system would presumably signal that output was being sent to the periphery and the type II fibers would presumably signal that the outer hair cells were responding either to this output or to sound. Whether small cells integrate these two inputs is not known because the responses of such cells have not been clearly demonstrated due to the difficulty in recording responses from small neurons. It now seems likely, though, that small cells in the lamina have a close relationship with afferent (type II) and efferent (medial olivocochlear) fibers associated with cochlear outer hair cells.

There are likely to be other sources of input to the small cells. For instance, one of the small cells received terminals with pleomorphic vesicles and both received terminals with small/round vesicles. This is a typical profile for endings in the small cell cap (Cant 1993). The pleomorphic vesicle terminals would be expected to have an inhibitory effect. These terminals could potentially originate in any of the many centers that project to the lamina (Itoh et al. 1987; Weinberg and Rustioni 1987; Burian and Gstoettner 1988; Kevetter and Perachio 1989; Caicedo and Herbert 1993; Saldana 1993; Weedman and Ryugo 1996). By contrast, these particular small cells do not appear to have received input from type I auditory nerve fibers in the areas that were examined because they received no terminals containing large/round vesicles that are typical of these fibers (Cant and Morest 1979; Treeck and Pirsig 1979; Tolbert and Morest 1982b). Type I terminals do not appear to be present in the granule-cell lamina (Mugnaini et al. 1980b; Cant 1993). As far as we could examine them, small dendrites including those of small cells, ran parallel to the granule-cell lamina and did not enter the magnocellular core. However, because the entire 
dendritic field of the small cells has not been reconstructed, it is impossible to say that there is no type I input to their dendrites. Nevertheless, these data suggest that cochlear-nucleus small cells of the subgroup examined here do not receive type I input. Such a situation is similar to the thin, unmyelinated (C) fibers of the somatosensory system, which terminate mainly in the superficial layers of the spinal dorsal horn, separately from the terminations of the thick myelinated fibers (Light and Perl 1979; Sugiura et al. 1986). Such separate terminations imply that the thin-fiber systems have separate functional processing of their information in the central nervous system. In the auditory system, these observations suggest the possibility of a small-cell circuit that operates without direct input from fibers associated with inner hair cells, the type I auditory nerve fibers.

\section{Convergence of type II, type I, and olivocochlear} inputs onto multipolar cells

Convergence of type II and type I input onto certain cochlear-nucleus neurons is suggested by some of our results, as summarized in the lower part of Figure 9. Such convergence is very likely to be present on the larger, principal neurons that are part of the magnocellular core of the cochlear nucleus. These targets include large neurons presumed to be multipolar cells and large dendrites that may emanate from them. Less common type II targets were a large neuron likely to be a globular bushy cell and a large neuron likely to be a spherical bushy cell in an earlier study (Berglund et al. 1996). All of these targets presumably receive type I input. Indeed, the bushy cells received endbulbs-a reliable marker of type I input. Principal cells examined in the present study are located at the dorsal edge of the cochlear nucleus just on the border of type I endings (on their ventral surfaces) and type II endings (on their dorsal surfaces, Fig. 6). Such examples of convergence suggest that several types of cochlear-nucleus neuron combine type I and type II input in their functional circuitry. How type II inputs add to the type I inputs, especially in the temporal realm, is unclear. Presumably, the type I input, which in the case of endbulbs presumably forms hundreds of synapses, would provide the dominant excitation.

The large dendrites that receive type II input are also likely to receive input from olivocochlear branches. Large dendrites in this region are the predominant target of these branches (Benson and Brown 1990), and in the present study one large dendrite target also received two unlabeled terminals forming synapses with postsynaptic bodies. We have previously outlined a functional scenario for the presumed multipolar cells that receive olivocochlear input (Benson and Brown 1990). Action of olivocochlear fibers on the periphery decreases the responses of auditory nerve fibers (Wiederhold and Kiang 1970; Guinan and Gifford 1988). Olivocochlear branches may compensate for the reduced nerve fiber input by exciting certain multipolar cells of the cochlear nucleus. Such a scenario receives support from electrophysiological studies (Mulders et al. 2003) and might be important for multipolar neuron involvement in coding for the absolute intensity of a sound. In fact, some of these neurons (Smith and Rhode 1989), as well as others in the marginal shell surrounding the cochlear nucleus (Ghoshal and Kim 1996), have the wide dynamic ranges that would be involved in coding for sound intensity. Presumably, type II input signals a response to sound or the action of olivocochlear fibers on the periphery. Further studies are needed to elucidate how this additional type II input would play a role.

\section{ACKNOWLEDGMENTS}

We thank Drs. J.J. Guinan, Jr., D.K. Lee, and M.C. Liberman for comments on an earlier version of the manuscript, and Dr. Wen Xu for technical help. Grant Sponsor: National Institute on Deafness and Other Communicative Disorders, National Institutes of Health, Grant Number DC 01089.

\section{REFERENCES}

Benson TE, Brown MC. Synapses formed by olivocochlear axon branches in the mouse cochlear nucleus. J. Comp. Neurol. 295:52-70, 1990 .

Benson TE, Berglund AM, Brown MC. Synaptic input to cochlearnucleus dendrites that receive medial olivocochlear synapses. J. Comp. Neurol. 365:27-41, 1996.

Berglund AM, Brown MC. Central trajectories of type-II spiral ganglion cells from various cochlear regions in mice. Hear. Res. 75:121-130, 1994.

Berglund AM, Benson TE, Brown MC. Synapses from labeled type II axons in the mouse cochlear nucleus. Hear. Res. 94:31-46, 1996.

Brawer JR, MoREST DK. Relations between auditory nerve endings and cell types in the cat's anteroventral cochlear nucleus seen with the Golgi method and Nomarski optics. J. Comp. Neurol. 160:491-506, 1975 .

Brawer JR, Morest DK, Kane EC. The neuronal architecture of the cochlear nucleus of the cat. J. Comp. Neurol. 155:251-300, 1974.

BRown MC. Morphology of labeled afferent fibers in the guinea pig cochlea. J. Comp. Neurol. 260:591-604, 1987.

Brown MC. Anatomical and physiological studies of type I and type II spiral ganglion neurons. In: Merchan MA, Juiz JM, Godfrey DA, Mugnaini E (Eds) The Mammalian Cochlear Nuclei: Organization and Function. Plenum Press, New York, pp 43-54, 1993.

Brown MC. Antidromic responses of single units from the spiral ganglion. J. Neurophysiol. 71:1835-1847, 1994. 
Brown MC, Ledwith JV III. Projections of thin (type-II) and thick (type-I) auditory-nerve fibers in the cochlear nucleus of the mouse. Hear. Res. 49:105-118, 1990.

Brown MC, Berglund AM, Kiang NYS, Ryugo DK. Central trajectories of type II spiral ganglion neurons. J. Comp. Neurol. 278:581-590, 1988a.

Brown MC, Liberman MC, Benson TE, Ryugo DK. Brainstem branches from olivocochlear axons in cats and rodents. J. Comp. Neurol. 278:591-603, 1988b.

Burian M, Gstoettner W. Projection of primary vestibular afferent fibres to the cochlear nucleus in the guinea pig. Neurosci. Lett. $84: 13-17,1988$

Caicedo A, Herbert H. Topography of descending projections from the inferior colliculus to auditory brainstem nuclei in the rat. J. Comp. Neurol. 328:377-392, 1993.

CANT NB. The fine structure of two types of stellate cells in the anterior division of the anteroventral cochlear nucleus of the cat. Neuroscience 6:2643-2655, 1981.

CANT NB. The cochlear nucleus: Neuronal types and their synaptic organization. In: Webster DB, Popper AN, Fay RR (Eds) The Mammalian Auditory Pathway: Neuroanatomy. Springer-Verlag, New York, pp 66-116, 1992.

CANT NB. The synaptic organization of the ventral cochlear nucleus of the cat: the peripheral cap of small cells. In: Merchan MA, Juiz JM, Godfrey DA, Mugnaini E (Eds) The Mammalian Cochlear Nuclei: Organization and Function. Plenum Press, New York, pp 91-106, 1993.

CANT NB, Morest DK. The bushy cells in the anteroventral cochlear nucleus of the cat. A study with the electron microscope. Neuroscience 4:1924-1945, 1979.

Doucet JR, Ryugo DK. Projections from the ventral cochlear nucleus to the dorsal cochlear nucleus in rats. J. Comp. Neurol. 385:245-264, 1997.

Fekete DM, Rouiller EM, Liberman MC, Ryugo DK. The central projections of intracellularly labeled auditory nerve fibers in cats. J. Comp. Neurol. 229:432-450, 1984.

Floris A, Dino M, Hacobowitz DM, Mugnaini E. The unipolar brush cells of the rat cerebellar cortex and cochlear nucleus are calretinin-positive: A study by light and electron microscopic immunocytochemistry. Anat. Embryol. 189:495-520, 1994.

GHoshal S, KIm DO. Marginal shell of the anteroventral cochlear nucleus: intensity coding in single units of the unanesthetized, decerebrate cat. Neurosci. Lett. 205:71-74, 1996.

Golding NL, Robertson D, Oertel D. Recordings from slices indicate that octopus cells of the cochlear nucleus detect coincident firing of auditory nerve fibers with temporal precision. J. Neurosci. 15:3138-3153, 1995.

GuinAn JJ Jr, GiFford ML. Effects of electrical stimulation of efferent olivocochlear neurons on cat auditory-nerve fibers. I. Ratelevel functions. Hear. Res. 33:97-114, 1988.

HackNey CM, Osen KK. The cochlear nucleus of the guinea pig: some light microscopic observations. Neurosci. Lett. Suppl. 21:S15, 1985

Hurd LB, Hutson KA, Morest DK. Cochlear nerve projections to the small cell shell of the cochlear nucleus: The neuroanatomy of extremely thin sensory axons. Synapse 33:83-117, 1999.

Hutson KA, Morest DK. Fine structure of the cell clusters in the cochlear nerve root: Stellate, granule, and mitt cells offer insights into the synaptic organization of local circuit neurons. J. Comp. Neurol. 371:397-414, 1996.

Itoh K, Kamiya H, Mitani A, Yasui Y, Takada M, Mizuno N. Direct projections from the dorsal column nuclei and the spinal trigeminal nuclei to the cochlear nuclei in the cat. Brain Res. 400:145-150, 1987.

Kevetter GA, Perachio AA. Projections from the sacculus to the cochlear nuclei in the Mongolian gerbil. Brain Behav. Evol. 34:193-200, 1989.
Kiang NYS, Rho JM, Northrop CC, Liberman MC, Ryugo DK. Haircell innervation by spiral ganglion cells in adult cats. Science 217:175-177, 1982.

Kiang NYS, Liberman MC, Gage JS, Northrop CC, Dodds LW, OLIVER ME. Afferent innervation of the mammalian cochlea. In: Bolis, Keynes RD, Maddrell SHP (Eds) Comparative Physiology of Sensory Systems. Cambridge University Press, Cambridge, pp 143-161, 1984.

Kopp-Scheinpflug C, Dehmel S, Dörrscheidt GI, Rübsamen R. Interaction of excitation and inhibition in anteroventral cochlear nucleus neurons that receive large endbulb synaptic endings. J. Neurosci. 22:11004-11018, 2002.

Liberman MC, Brown MC. Physiology and anatomy of single olivocochlear neurons in the cat. Hear. Res. 24:17-36, 1986.

Light AR, PerL ER. Reexamination of the dorsal root projection to the spinal dorsal horn including observations on the differential termination of coarse and fine fibers. J. Comp. Neurol. 186:117$132,1979$.

LORENTE DE No R. Anatomy of the eighth nerve. The central projection of the nerve endings of the internal ear. Laryngoscope 43:1-38, 1933.

MARTIN MR. Acetylcholinesterase-positive fibers and cell bodies in the cochlear nuclei of normal and reeler mutant mice. J. Comp. Neurol. 197:153-167, 1981.

Morrison D, Schindler RA, Wersall J. A quantitative analysis of the afferent innervation of the organ of Corti in guinea pig. Acta Otolaryngol. 79:11-23, 1975.

Mugnaini E, Osen KK, Dahl A-L, Friedrich VL Jr, Korte G. Fine structure of granule cells and related interneurons (termed Golgi cells) in the cochlear nuclear complex of cat, rat, and mouse. J. Neurocytol. 9:537-570, 1980a.

Mugnaini E, WarR WB, Osen KK. Distribution and light microscopic features of granule cells in the cochlear nucleus of cat, rat, and mouse. J. Comp. Neurol. 191:581-606, 1980.

Mulders Wham, Paolini AG, Needham K, Robertson D. Olivocochlear collaterals evoke excitatory effects in onset neurones of the rat cochlear nucleus. Hear. Res. 176:113-121, 2003.

Oertel D, Wu SH, Garb MW, Dizack C. Morphology and physiology of cells in slice preparations of the posteroventral cochlear nucleus of mice. J. Comp. Neurol. 295:136-154, 1990.

OsEn KK. Cytoarchitecture of the cochlear nuclei in the cat. J. Comp. Neurol. 136:453-484, 1969.

Osen KK, Mugnaini E, Dahl A-L, Christiansen AH. Histochemical localization of acetylcholinesterase in the cochlear and superior olivary nuclei. A reappraisal with emphasis on the cochlear granule cell system. Arch. Ital. Biol. 122:169-212, 1984.

Pfeiffer RR. Anteroventral cochlear nucleus: Wave forms of extracellularly recorded spike potentials. Science 154:667-668, 1966.

RASMUSSEN GL. Efferent fibers of the cochlear nerve and cochlear nucleus. In: Rasmussen GL, Windle W (Eds) Neural Mechanisms of the Auditory and Vestibular Systems. C.C. Thomas, Springfield IL, pp 105-115, 1960.

ROBERTSON D. Horseradish peroxidase injection of physiologically characterized afferent and efferent neurons in the guinea pig spiral ganglion. Hear. Res. 15:113-121, 1984.

Robertson D, Gummer M. Physiological and morphological characterization of efferent neurons in the guinea pig cochlea. Hear. Res. 20:63-77, 1985.

Robertson D, Sellick PM, Patuzzi R. The continuing search for outer hair cell afferents in the guinea pig spiral ganglion. Hear. Res. 136:151-158, 1999.

Romand MR, Romand R. The ultrastructure of spiral ganglion cells in the mouse. Acta Otolaryngol. 104:29-39, 1987.

Rouiller EM, Cronin-Schreiber R, Fekete DM, Ryugo DK. The central projections of intracellularly labeled auditory nerve fibers in cats: An analysis of terminal morphology. J. Comp. Neurol. 249:261-278, 1986. 
RUGGero MA. Physiology and coding of sound in the auditory nerve. In: Popper AN, Fay RR (Eds) The Mammalian Auditory Pathway: Neurophysiology. Springer-Verlag, New York, pp 34-93, 1992.

Ryan AF, Schwartz IR, Helfert RH, Keithley E, Wang ZX. Selective retrograde labeling of lateral olivocochlear neurons in the brainstem based on preferential uptake of 3H-D-aspartic acid in the cochlea. J. Comp. Neurol. 255:606-616, 1992.

Ryugo DK, Dodds LW, Benson TE, KIANG NYS. Unmyelinated axons of the auditory nerve in cats. J. Comp. Neurol. 308:209-223, 1991.

Saldana E. Descending projections from the inferior colliculus to the cochlear nuclei in mammals. In: Merchan MA, Juiz JM, Godfrey DA, Mugnaini E (Eds) The Mammalian Cochlear Nuclei: Organization and Function. Plenum Press, New York, pp 153-165, 1991.

Schwartz AM, Gulley RL. Non-primary afferents to the principal cells of the rostral anteroventral cochlear nucleus of the guineapig. Am. J. Anat. 153:489-508, 1978.

Smith PH, Rhode WS. Structural and functional properties distinguish two types of multipolar cells in the ventral cochlear nucleus. J. Comp. Neurol. 282:595-616, 1989.

SPoEndLIN HH. Innervation patterns in the organ of Corti of the cat. Acta Otolaryngol. 67:239-254, 1969.

Spoendin H. Degeneration behavior of the cochlear nerve. Arch. Klin. Exp. Ohren Nasen Kehlkopfheilkd. 200:275-291, 1971.
Sugiura Y, Lee CL, Perl ER. Central projections of identified, unmyelinated (C) afferent fibers innervating mammalian skin. Science 234:358-361, 1986.

TOLBERT LP, MOREST DK. The neuronal architecture of the anteroventral cochlear nucleus of the cat in the region of the cochlear nerve root: Electron microscopy. Neuroscience 7:3053-3067, 1982

Treeck H-H, Pirsig W. Differentiation of nerve endings in the cochlear nucleus on morphological and experimental basis. Acta Otolaryngol. 87:47-60, 1979.

UChizono K. Characteristics of excitatory and inhibitory synapses in the central nervous system of the cat. Nature 207:642-643, 1965.

Weedman DL, Ryugo DK. Projections from auditory cortex to the cochlear nucleus in rats: Synapses on granule cell dendrites. J. Comp. Neurol. 371:311-324, 1996.

Weedman DL, Pongstaporn T, Ryugo DK. Ultrastructural study of the granule cell domain of the cochlear nucleus in rats: Mossy fiber endings and their targets. J. Comp. Neurol. 369:345-360, 1996.

Weinberg RJ, Rustioni A. A cuneocochlear pathway in the rat. Neuroscience 20:209-219, 1987.

WiEDERHOLD ML, KIANG NYS. Effects of electric stimulation of the crossed olivocochlear bundle on single auditory-nerve fibers in the cat. J. Acoust. Soc. Am. 48:950-965, 1970. 